\title{
The effects of organic acids, phytates and polyphenols on the absorption of iron from vegetables
}

\author{
BY M. GILLOOLY, T. H. BOTHWELL*, J. D. TOR RANCE, \\ A. P. MACPHAIL, D. P. DERMAN, W. R. BEZWODA, W. MILLS \\ AND R. W. CHARLTON \\ Joint University/South African MRC Iron and Red Cell Metabolism Unit, Department of \\ Medicine, University of the Witwatersrand, Medical School, York Road, Parktown, \\ Johannesburg, 2193 South Africa \\ AND FATIMA MAYET \\ Department of Medicine, University of Natal, Durban, South Africa
}

\section{(Received 23 August 1982 - Accepted 20 December 1982)}

1. Non-haem iron absorption from a variety of vegetable meals was studied in parous Indian Women, using the erythrocyte utilization of radioactive Fe method.

2. The studies were undertaken to establish whether Fe absorption could be correlated with the chemical composition of the foodstuff.

3. Addition of the following organic acids commonly found in vegetables, improved the geometric mean Fe absorption from a basic rice meal as follows: from 0.028 to 0.085 with $1 \mathrm{~g}$ citric acid, from 0.031 to 0.081 with $15 \mathrm{mg}$ ascorbic acid, from 0.048 to 0.095 with $1 \mathrm{~g} \mathrm{~L}$-malic acid, from 0.041 to 0.096 with $1 \mathrm{~g}$ tartaric acid. The only exception was oxalic acid; the addition of $1 \mathrm{~g}$ calcium oxalate to cabbage (Brassica oleraceae) was associated with some depression in Fe absorption from 0.320 to 0.195.

4. There was a marked inhibition of the geometric mean absorption when $500 \mathrm{mg}$ tannic acid was added to a broccoli (Brassica oleraceae) meal $(0.015$ v. 0.297). Sodium phytate ( $2 \mathrm{~g})$ caused a similar, though less profound inhibition $(0.035$ to 0.152$)$.

5. When $3 \mathrm{mg}$ ferrous sulphate was added to different vegetables the geometric mean absorption varied widely. Vegetables of low Fe bioavailability were wheat germ (Triticum aestivum) $0 \cdot 007$, aubergine (Solanum melongena) 0.007, butter beans (Phaseolus lunatus) 0.012 , spinach (Spinacea oleraceae) 0.014 , brown lentils (Lens culinaris) 0.024 , beetroot greens (Beta vulgaris) 0.024 and green lentils (Lens culinaris) 0.032 . In contrast, bioavailability was moderate or good with carrot (Daucus carota) 0.098 , potato (Solanum tuberosum) $0 \cdot 115$, beetroot (Beta vulgaris) $0 \cdot 185$, pumpkin (Cucurbita mixta) 0.206 , broccoli 0.260 , tomato (Lycopersicon esculentum) 0.224 , cauliflower (Brassica oleraceae) 0.263, cabbage 0.320, turnip (Brassica rapa) 0.327 and sauerkraut 0.327.

6. All the vegetables associated with moderate or good $\mathrm{Fe}$ bioavailability contained appreciable amounts of one or more of the organic acids, malic, citric and ascorbic acids.

7. Poor Fe bioavailability was noted in vegetables with high phytate contents (e.g. wheat germ 0.007 , butter beans $0 \cdot 012$, brown lentils 0.024 and green lentils $0 \cdot 032$ ).

8. The fact that a number of vegetables associated with low Fe-absorption turned bluish-black when Fe was added to them, suggested that the total polyphenol content in them was high. The vegetables included aubergine, spinach, brown lentils, green lentils and beetroot greens. When the total polyphenol content in all the vegetables tested was formally measured, there was a significant inverse correlation $(r 0.859, P<0.001)$ between it and Fe absorption. The inverse correlation between the non-hydrolysable polyphenol content and Fe absorption was $r$ $0.901(P<0.001)$.

9. The major relevance of these findings is the fact that the total absorption of non-haem-Fe from a mixed diet may be profoundly influenced by the presence of single vegetables with either marked enhancing or inhibiting effects on Fe bioavailability.

In many parts of the world the average diet is predominantly cereal in nature, wheat, rice and maize forming the major staples. Although many of these diets appear to contain sufficient Fe (Apte \& Iyengar, 1970; Hallberg, 1974), Fe bioavailability is poor (Martinez-

* For reprints. 
Torres \& Layrisse, 1973). During digestion the non-haem-Fe in vegetables and cereals enters a 'common pool' where its absorption is influenced by various enhancers or inhibitors (Cook et al. 1972; Hallberg \& Bjorn-Rasmussen, 1972). The major known enhancers of $\mathrm{Fe}$ absorption are ascorbic acid (Sayers et al. 1973, 1974a, b; Disler, Lynch, Charlton, Bothwell et al. 1975; Derman et al. 1977) and meat (Layrisse et al. 1973; Cook \& Monsen, 1976). Ascorbic acid owes this ability to its reducing properties and to its ability to chelate $\mathrm{Fe}$. Its promoting influence on $\mathrm{Fe}$ absorption is dose dependent (Sayers et al. 1973; Bjorn-Rasmussen \& Hallberg, 1974; Derman, Bothwell, MacPhail et al. 1980) and in diets containing little or no meat, the ascorbic acid content of the components of a meal has, therefore, been regarded as the crucial factor in determining its Fe nutritive value. Its efficacy is illustrated by the report that the addition of cauliflower containing approximately $70 \mathrm{mg}$ ascorbic acid to a vegetarian meal trebled the amount of Fe absorbed (Hallberg, 1981). Ascorbic acid is only one of the several organic acid constituents of fruit and vegetables however, and there is little information concerning the possible role of the others.

Inhibitors of $\mathrm{Fe}$ absorption present in vegetable foods may also exert a profound influence on Fe nutrition. Sodium phytate has been reported to have such an effect (Turnbull et al. 1962; Hallberg, 1981), and it occurs in a number of plants as a phosphorus reserve storage compound (van Soest, 1978). Another established inhibitor is the tannin in tea (Disler, Lynch, Charlton, Torrance et al. 1975; Disler, Lynch, Torrance et al. 1975); other tannins or polyphenols are present in many vegetable foods, but there is little information concerning any influence they might exert. Therefore, a detailed study of $\mathrm{Fe}$ absorption from a number of vegetables was undertaken in order to obtain some insight into the relative contributions of these various factors to the bioavailability of dietary non-haem-Fe.

\section{EXPERIMENTAL}

\section{Subjects}

A group of 180 parous Indian housewives took part in these studies. None of the subjects was pregnant or lactating and all were unpaid volunteers. Their ages ranged between 21 and 76 years (mean 39 years) and all belonged to a low socio-economic group living in municipal housing schemes in Chatsworth and Merebank, near Durban. It has previously been established that $\mathrm{Fe}$ deficiency is a common problem among the women of this community (Mayet et al. 1972; MacPhail et al. 1981).

\section{Preparation and administration of the meals}

The absorption of radio-labelled-Fe that had been mixed with the vegetables listed in Tables 3 and 4 (see pp. 337 and 338), or with rice, was measured. In each absorption study two meals were consumed on consecutive mornings after an overnight fast. Only water was permitted during the meal and for a period of $3 \mathrm{~h}$ afterwards.

Vegetable meals. Each subject received a meal that was equivalent to $50 \mathrm{~g}$ of the uncooked vegetable. Preparation was as follows: $750 \mathrm{~g}$ portions of the vegetables were weighed (after peeling in the case of pumpkin, carrots, potato, beetroot and turnip) and cooked in $1500 \mathrm{ml}$ boiling water with $5 \mathrm{~g}$ table salt (sodium chloride) for $20 \mathrm{~min}$. Lentils were cooked in $2500 \mathrm{ml}$ water for $\mathbf{4 0} \mathrm{min}$. The cooked vegetable was homogenized in a Waring blender to the consistency of a thick soup, and each subject consumed $100 \mathrm{~g}$ of it after the radio-labelled-Fe had been mixed in.

Rice meal. Polished parboiled rice $(1 \mathrm{~kg}$ ) was boiled for $20 \mathrm{~min}$ in $2000 \mathrm{ml}$ water containing $20 \mathrm{~g}$ table salt. After boiling, $75 \mathrm{~g}$ yellow margarine and $150 \mathrm{~g}$ sucrose were added. Each person received $215 \mathrm{~g}$ of the 'pudding' with the radio-labelled-Fe solution 
thoroughly stirred in, on one of the two occasions together with the organic acid under investigation. However, tannic acid was given as a drink with sugar and water, since a dark colour developed when added to the meal that made the meal appear unpalatable.

\section{Measurement of Fe absorption}

$\mathrm{Fe}$ as $\mathrm{FeSO}_{4} \cdot 7 \mathrm{H}_{2} \mathrm{O}(3 \mathrm{mg})$ in solution was thoroughly mixed with each individual's serving. On one morning it was labelled with $3 \mu \mathrm{Ci}{ }^{59} \mathrm{Fe}$ and on the other with $3 \mu \mathrm{Ci}{ }^{55} \mathrm{Fe}$ (Amersham International, Amersham, Bucks). After 2 weeks, blood for the determination of ${ }^{59} \mathrm{Fe},{ }^{55} \mathrm{Fe}$, haemoglobin, serum $\mathrm{Fe}$, unsaturated Fe-binding capacity and serum ferritin was obtained from each subject after she had fasted overnight. Each person then drank a solution of $3 \mathrm{mg} \mathrm{Fe}$ as $\mathrm{FeSO}_{4} .7 \mathrm{H}_{2} \mathrm{O}$ labelled with $3 \mu \mathrm{Ci}{ }^{59} \mathrm{Fe}$ to which $30 \mathrm{mg}$ ascorbic acid had been added. Only water was permitted during the following $3 \mathrm{~h}$. Blood samples were obtained $14 \mathrm{~d}$ later, and the absorption of this Fe was determined from the increment in ${ }^{59} \mathrm{Fe}$ in the blood. By expressing the absorption of $\mathrm{Fe}$ from the meals relative to the absorption of this reference iron salt, a basis for comparing results in individuals of differing Fe nutritional status was established (Rossander et al. 1979; Hallberg, 1981).

\section{Radioisotopic, chemical and statistical methods}

Duplicate $10 \mathrm{ml}$ blood samples and duplicate portions of standard Fe solutions were prepared for differential radioactive counting using the method of Eakins \& Brown (1966). The activities of ${ }^{55} \mathrm{Fe}$ and ${ }^{59} \mathrm{Fe}$ in the processed samples were determined in Insta-Gel scintillant (Packard Instrument Co., Downers Grove, Illinois), using a liquid-scintillation spectrometer (Packard-Tri-Carb AAA Spectrometer Model no. 3375) which automatically corrected for quenching. The counting efficiency at optimal gain and window settings was $24 \%$ for ${ }^{55} \mathrm{Fe}$ and $42 \%$ for ${ }^{59} \mathrm{Fe}$. The ${ }^{59} \mathrm{Fe}$ activity in $4-\mathrm{ml}$ blood samples collected immediately before the reference Fe salt was administered, and 2 weeks later, was assessed against suitable standards using a Packard Auto Gamma scintillation spectrometer no. 5320 , with a counting efficiency of $60 \%$. The absorption values were calculated on the basis that $100 \%$ of the absorbed radioactivity was present in the haemoglobin of the circulating erythrocytes, and that the blood volume for each subject was $65 \mathrm{ml} / \mathrm{kg}$ body-weight. The calculated food Fe absorptions were then corrected to an absorption of 0.40 for the reference Fe salt as follows:

$$
\text { corrected food } \mathrm{Fe} \text { absorption }=\frac{\text { calculated food Fe absorption } \times 0.40}{\text { calculated reference Fe salt absorption }} \text {. }
$$

A value of 0.40 was chosen as the reference point, since it represents approximately the amount absorbed by subjects who lack Fe stores but are not yet anaemic (Hallberg, 1981); the corrected food $\mathrm{Fe}$ absorptions would therefore be expected to provide a sensitive indicator of the relative bioavailability of $\mathrm{Fe}$ in different meals. The Fe absorptions and the ferritin concentrations were expressed as geometric means and standard deviation ranges, since individual experiments showed considerable variation, with positive skewing. The significance of differences between the corrected absorptions of the two isotopes used in each study was calculated using Student's $t$ test for paired observations.

Haemoglobin concentrations were determined by the cyanmethaemoglobin technique. Serum $\mathrm{Fe}$ concentrations and unsaturated $\mathrm{Fe}$-binding capacities were measured using the methods of the International Committee for Standardisation in Haematology $(1978 a, b)$. Serum ferritin was measured using the ELISA radioimmunoassay technique of Conradie \& Mbhele (1980). The total and extractable polyphenol contents of vegetables were measured by a modification of the method of Singleton \& Rossi (1965). 


\section{Ethical considerations}

Approval for the studies to be performed was obtained from the Committee for Research on Human Subjects of the Faculty of Medicine, University of the Witwatersrand, Johannesburg. Written consent was obtained from all subjects after the nature of the investigation had been fully explained to them by an Indian social worker. Each subject took part in one experiment only. It was calculated that if each test dose was completely retained, the total radiation dosage would be 143 mrems (Bothwell et al. 1979) which is $28 \%$ of the annual maximum permissible dose for members of the public (International Commission for Radiation Protection, 1960; South African Bureau of Standards, 1972). In practice the percentage absorbed is much less which makes the radiation exposure proportionately smaller.

\section{RESULTS}

The effect of various organic acids on Fe absorption from a rice meal

As expected, $\mathrm{Fe}$ absorption from the unsupplemented rice was low, ranging between 0.028 and 0.049 (Table 1). In the first study the amount of ascorbic acid present in an equivalent weight of potatoes (i.e. $15 \mathrm{mg}$ ) was found to increase Fe absorption to 0.081 . An equimolar amount of citric acid (BDH Lab. Chemicals Div., Poole, Dorset) produced a mean absorption of 0.099 , but this was not significantly higher than from the unsupplemented rice $(t 1 \cdot 51, P>0 \cdot 1)$. However, a highly-significant improvement occurred when the amount of citric acid was increased to $1 \mathrm{~g}$, the absorption trebling from 0.028 to $0.085(t 4.7$, $P<0.0005$ ). When $1 \mathrm{~g}$ tartaric acid (Analytical Grade; Merck, Darmstadt) was substituted, the mean absorption increased from 0.041 to $0.096(t 2.5, P<0.025)$, and with $1 \mathrm{~g} \mathrm{~L}$-malic acid (Sigma Chemical Co., St Louis) it rose from 0.048 to 0.095 ( $t 2.8, P<0.025$ ).

In a final experiment, $1 \mathrm{~g}$ calcium oxalate (BDH Chemicals, Poole, Dorset) was added to cabbage and the effect on the absorption of Fe was examined. There was a moderate depression from a geometric mean of 0.320 (SD 0.192-0.532) to $0 \cdot 195$ (SD 0.103-0.370) $(t 3 \cdot 1, P<0 \cdot 01)$.

\section{Effect of sodium phytate and of tannic acid on Fe absorption}

The effect of two possible inhibitors of $\mathrm{Fe}$ absorption was tested by adding them to broccoli (Table 2). In the first experiment, $2 \mathrm{~g}$ sodium phytate reduced the geometric mean $\mathrm{Fe}$ absorption from 0.152 to $0.035(t 4.8, P<0.0005)$, while in the second experiment $500 \mathrm{mg}$ of the polyphenolic compound tannic acid diminished it from 0.297 to 0.0150 ( $t 6.0$, $P<0.0001)$.

\section{Factors affecting the absorption of Fe from a number of vegetables}

There was a wide range in $\mathrm{Fe}$ absorption from the seventeen vegetables studied (Table 3), the lowest being wheat germ (0.007) and the two highest turnip $(0.327)$ and sauerkraut $(0.327)$. Since it seemed likely that the variations might, in part, be due to differences in the concentrations of inhibitors and enhancers of $\mathrm{Fe}$ absorption in individual vegetables, an attempt was made to relate the absorption findings to the concentrations of phytate and organic acids contained within them according to published tables (Diem \& Lentner, 1970; Paul \& Southgate, 1976) (Table 4).

The vegetables could be divided into two distinct groups with regard to $\mathrm{Fe}$ absorption. In the first, which included wheat germ (0.007), aubergine $(0.007)$, butter beans $(0.012)$, spinach (0.014), brown lentils $(0.024)$, beetroot greens $(0.024)$ and green lentils $(0.032)$, the bioavailability of $\mathrm{Fe}$ was poor. In the second group the bioavailability was moderate or good, namely carrot $(0 \cdot 098)$, potato $(0 \cdot 115)$, beetroot $(0 \cdot 185)$, pumpkin $(0 \cdot 206)$, broccoli 


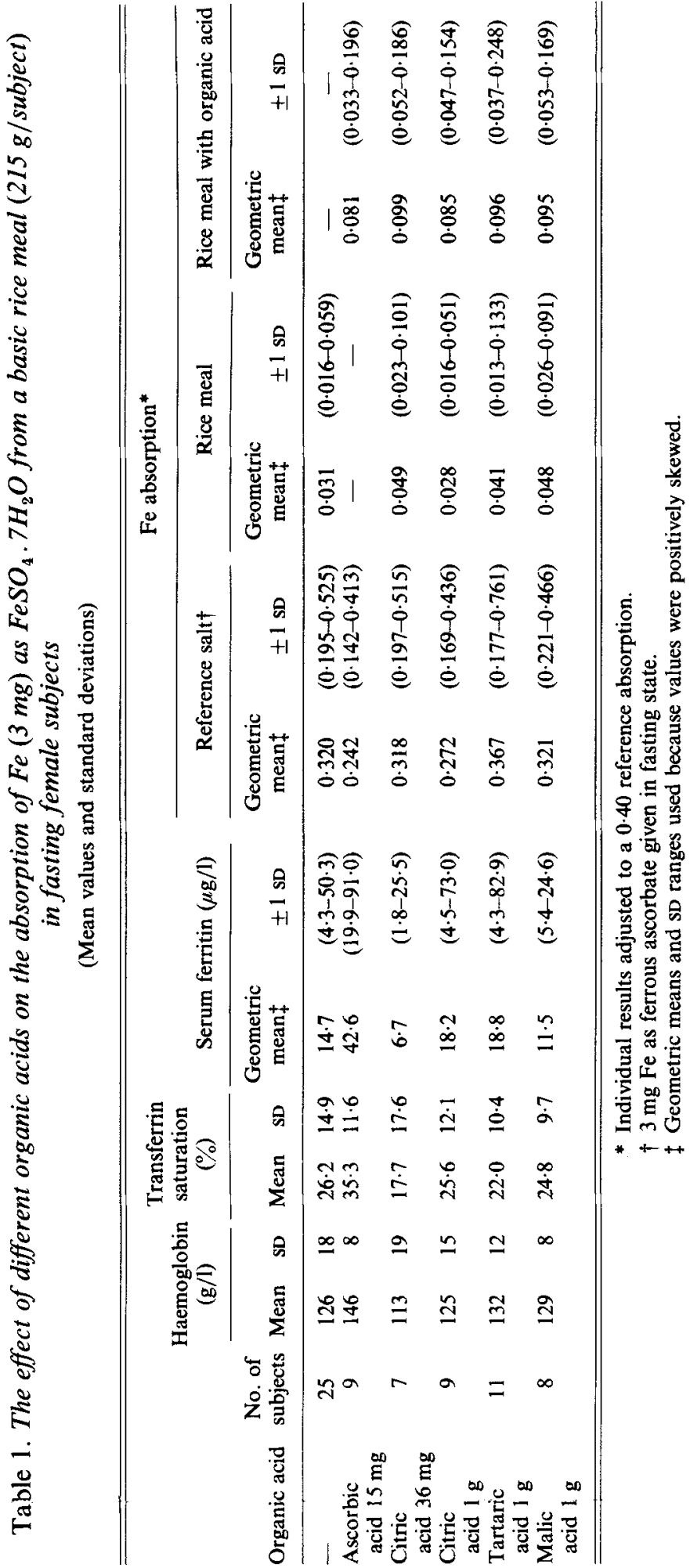




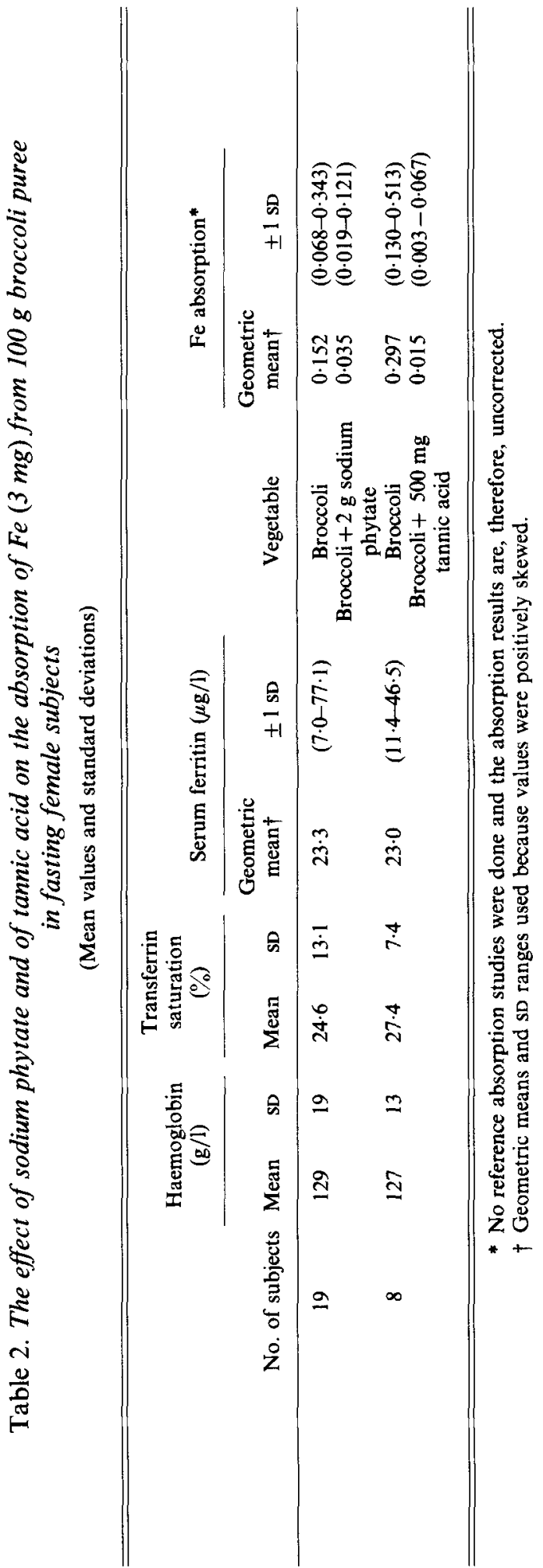




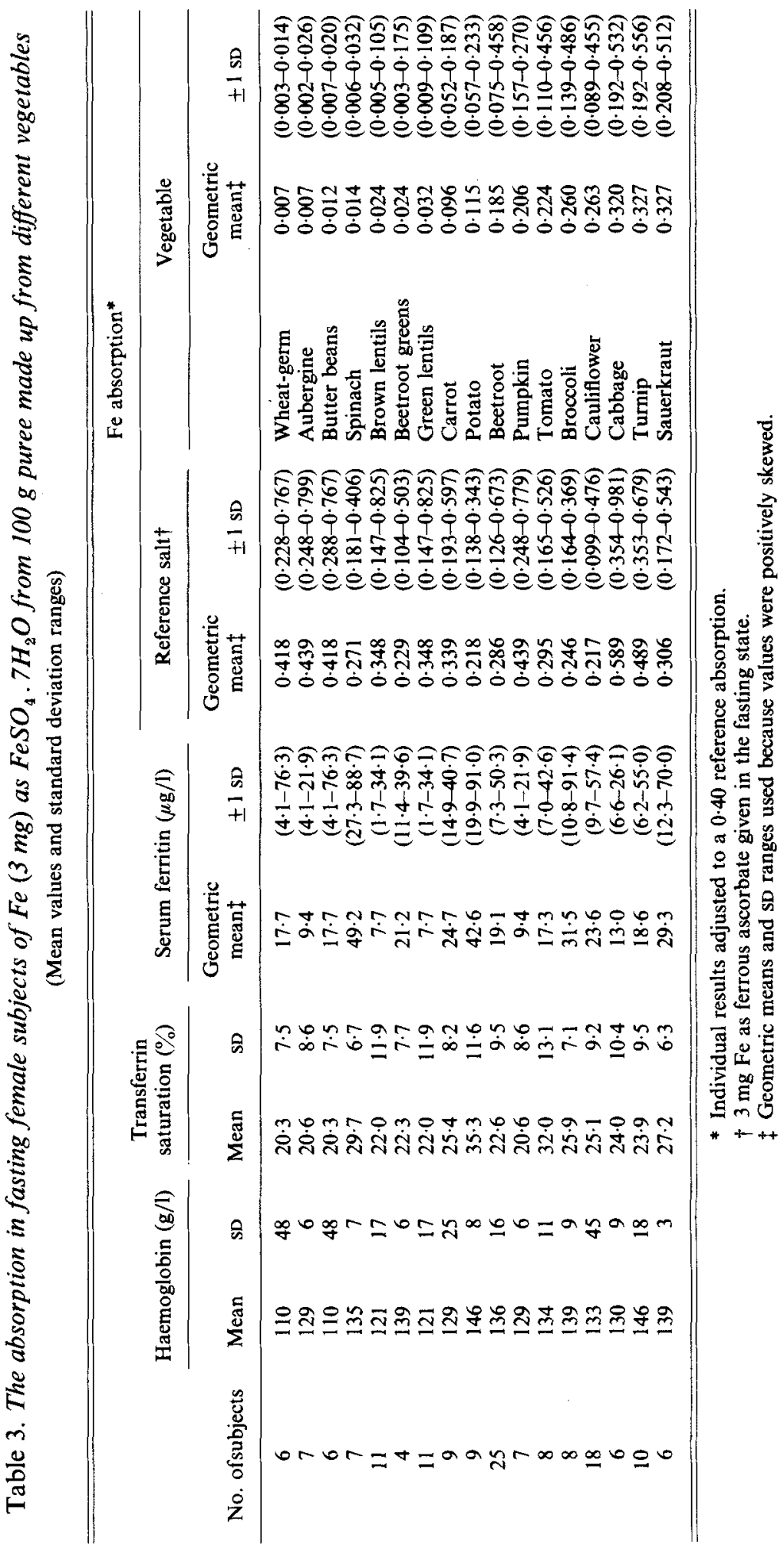


Table 4. Phosphorus, polyphenol and organic acid contents of vegetables

\begin{tabular}{|c|c|c|c|c|c|c|c|}
\hline & \multirow{2}{*}{$\begin{array}{l}\text { Phosphorus } \\
(\mathrm{mg} / \mathrm{kg})^{*}\end{array}$} & \multicolumn{2}{|c|}{ Polyphenols (mg/g) } & \multicolumn{4}{|c|}{ Organic acids (mg/kg edible portion) $)^{*}$} \\
\hline & & Total & Extractable & Malic & Citric & Oxalic & Ascorbic \\
\hline Wheat germ & 11180 & 8.4 & $2 \cdot 0$ & 0 & 3400 & 0 & 0 \\
\hline Aubergine & 150 & $3 \cdot 4$ & 0.4 & 170 & 0 & 70 & 50 \\
\hline Butter beans & 3200 & $3 \cdot 5$ & $0 \cdot 6$ & - & - & -- & 0 \\
\hline Spinach & 510 & 6.9 & $1 \cdot 1$ & 90 & 800 & 4600 & 500 \\
\hline Brown lentils & 3800 & 6.8 & 1.8 & 0 & 0 & 0 & 0 \\
\hline Beetroot greens & 40 & 6.6 & $2 \cdot 3$ & 0 & 0 & 9200 & 300 \\
\hline Green lentils & 3800 & $6 \cdot 3$ & $2 \cdot 9$ & 0 & 0 & 0 & 0 \\
\hline Carrot & 360 & 0.9 & $0 \cdot 2$ & 24 & 900 & 330 & 100 \\
\hline Potato & 530 & 0.9 & 0.7 & 0 & 5100 & 60 & 200 \\
\hline Beetroot & 330 & $2 \cdot 4$ & 0.9 & 0 & 1100 & 3400 & 100 \\
\hline Pumpkin & 440 & 0.7 & 0.6 & 150 & 0 & 0 & 90 \\
\hline Tomato & 270 & 0.6 & 0.3 & 150 & 3900 & 80 & 230 \\
\hline Broccoli & 780 & $3 \cdot 2$ & 2.8 & 120 & 2100 & 0 & 1130 \\
\hline Cauliflower & 560 & 1.6 & 0.9 & 390 & 2100 & 0 & 780 \\
\hline Cabbage & 270 & 0.7 & 0.6 & 0 & 0 & 0 & 460 \\
\hline Turnip & 300 & $0 \cdot 9$ & 0.6 & 230 & 0 & 0 & 360 \\
\hline Sauerkraut & 180 & $0 \cdot 6$ & 0.4 & $0 \dagger$ & $0 \dagger$ & $0+$ & 140 \\
\hline
\end{tabular}

* Values from Diem \& Lentner (1970) and Paul \& Southgate (1976).

$\dagger$ Lactic acid $1600 \mathrm{mg} / \mathrm{kg}$.

$(0 \cdot 260)$, cauliflower $(0 \cdot 263)$, tomato $(0 \cdot 224)$, cabbage $(0 \cdot 320)$, turnip $(0 \cdot 327)$ and sauerkraut $(0.327)$. All except one of the second group of vegetables contained reasonable quantities of one or more of the organic acids, malic, citric and ascorbic acids. The exception was sauerkraut, which contains a large amount of lactic acid. The role of organic acids was further defined in another experiment in which broccoli was given with and without the cooking water in which it was boiled, since a significant proportion of the acids in the broccoli would be dissolved in the water. Haematological information on the ten housewives who took part in this study were as follows: mean haemoglobin concentration $14.0 \mathrm{~g} / 1$ (SD 0.95 ), mean transferrin saturation $27 \cdot 1 \%$ (SD 6.9), geometric mean serum ferritin concentration $41 \cdot 3 \mu \mathrm{g} / 1$ (SD 12.8-133.7) and geometric mean reference absorption $0 \cdot 205$ (SD $0 \cdot 106-0 \cdot 398)$. When the broccoli was given with the cooking water the corrected geometric mean Fe absorption was 0.253 (SD 0.148-0.432) compared with 0.115 (SD 0.068-0.193) when the water was discarded $(t 4 \cdot 1, P<0.005)$. No relationship between oxalate content and Fe absorption emerged when the three vegetables that contained large amounts of oxalate were examined: Fe absorption was poor from spinach and beetroot greens and good from beetroot. On the other hand the $\mathbf{P}$ and, therefore, presumably the phytate contents, were high in wheat germ, butter beans and lentils, in all of which the Fe bioavailability was low.

The results of a further experiment raised the possibility that the polyphenols present in certain vegetables might also exert a profound effect on $\mathrm{Fe}$ absorption. A $10 \mathrm{~g}$ ferric chloride/ 1 solution was added to individual vegetables, since it has previously been shown that when ferric salts are added to a solution containing polyphenols a bluish-black discoloration develops due to the formation of coloured Fe complexes (Seikel, 1964; Disler, Lynch, Torrance et al. 1975). Marked darkening of aubergine, spinach, green and brown lentils and beetroot greens was noted, and the bioavailability of the $\mathrm{Fe}$ in each had been found to be low. In contrast, a vegetable such as pumpkin, from which Fe was well absorbed, did not darken noticeably when Fe was added. The total polyphenol content 


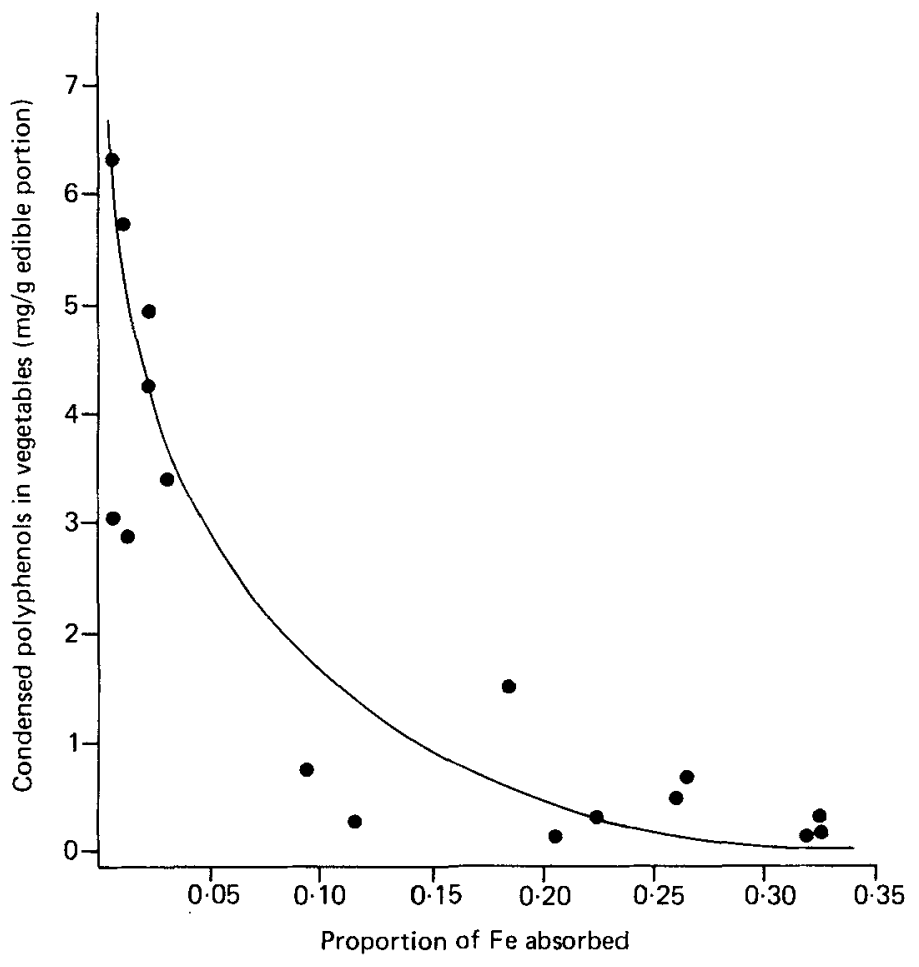

Fig. 1. The inverse correlation between the condensed polyphenol content of vegetables (total-extractable polyphenols) and $\mathrm{Fe}$ absorption from them. The line is derived from the least squares regression after square-root transformation $(r-0.90)$.

of all the vegetables was therefore measured (Table 4) and a significant inverse correlation with $\mathrm{Fe}$ absorption was noted $(r-0.859 ; P<0.001)$. It seemed that the effect was due to condensed rather than to hydrolysable polyphenols, since the inverse correlation was even closer $(r-0.901 ; P<0.001)$ when the amounts of extractable polyphenols had been subtracted (Fig. 1). In these analyses square-root conversion of the values was used as this normalized the values which were otherwise positively skewed.

\section{DISCUSSION}

Fe deficiency has been shown to be a common problem in the Indian population in which this series of studies was undertaken, with a $26 \%$ prevalence in the females (Mayet et al. 1972; MacPhail et al. 1981). These findings were confirmed by our present results, which showed that the geometric mean serum ferritin level in most of the groups of women was a good deal less than the normal value of $35 \mu \mathrm{g} / \mathrm{l}$.

In each experiment, $3 \mathrm{mg}$ inorganic Fe labelled with radioactive-Fe was added to the meal and the absorption of the isotope measured. The results reflected the absorption of not only the added $\mathrm{Fe}$ but also the intrinsic rice or vegetable $\mathrm{Fe}$, since it has previously been well established that there is free isotopic exchange within the lumen of the gastrointestinal tract under such circumstances (Bothwell et al. 1979; Hallberg, 1981).

In the first series of studies, different organic acids were added to a rice meal to examine their individual effects. Citric, tartaric and malic acids in $1 \mathrm{~g}$ quantities were each found to increase $\mathrm{Fe}$ absorption significantly. These findings may well have relevance to $\mathrm{Fe}$ nutrition since citrus fruits, such as oranges, lemons and grapefruit, contain a minimum of 
$10 \mathrm{~g}$ citric acid $/ \mathrm{kg}$, while malic acid is found in the deciduous fruits such as plums, peaches and apples, in concentrations ranging from $3 \mathrm{~g} / \mathrm{kg}$ to greater than $10 \mathrm{~g} / \mathrm{kg}$ (Diem \& Lentner, 1970; Paul \& Southgate, 1976). Tartaric acid is not present in vegetables but is found in concentrations ranging from $1630-2340 \mathrm{mg} / \mathrm{kg}$ in white wines (see Diem \& Lentner, 1970) and may play a part in the high bioavailability of the $\mathrm{Fe}$ they contain. Although the concentrations of individual organic acids in vegetables are not notably high, they usually contain more than one of them, and much of the considerable variation in the bioavailability of the Fe given with different vegetables in the present study could be ascribed to differences in the content of malic, citric and ascorbic acids (Table 4). Carrots, potato, beetroot, pumpkin, broccoli, cauliflower, tomato, cabbage and turnip were associated with good $\mathrm{Fe}$ bioavailability and contained one or more of the organic acids in reasonable concentrations. Ascorbic acid appeared to be the major promoting agent in cabbage, and malic acid in pumpkin, but in other vegetables it was not possible to dissect out the individual effects of the different acids. The good absorption of Fe from sauerkraut may have been due to its high lactic acid content, since this acid has previously been shown to be an effective promoter (Derman, Bothwell, Torrance et al. 1980). The high bioavailability of $\mathrm{Fe}$ in some of these vegetables was underlined by the fact that the absorption from cabbage, turnip and sauerkraut was as much as $80 \%$ of that of a $3 \mathrm{mg}$ reference dose of ferrous ascorbate.

Meat is an important dietary constituent for adequate Fe nutrition, since it not only potentiates the absorption of the non-haem-Fe in the meal, but it also contains haem-Fe which is well absorbed since it is not vulnerable to any inhibitory ligands that may be present (Layrisse et al. 1969; Cook \& Monsen, 1976; Monsen et al. 1978). The low meat intake of many populations has, therefore, been regarded as one of the factors responsible for the widespread occurrence of dietary Fe deficiency, and the critical importance for Fe nutrition of the ascorbic acid content of such diets has been stressed. In the present series of experiments, however, it was possible to show that ascorbic acid is just one of several organic acids which potentiate non-haem-Fe absorption, although it is the most potent of them.

The one organic acid that was found to have a moderate depressing effect on $\mathrm{Fe}$ absorption was oxalic acid. However, its role, if any, in modifying the bioavailability of $\mathrm{Fe}$ in vegetables was not clearly elucidated. While the addition of calcium oxalate, which is one of the two major salts of oxalic acid in vegetables (Diem \& Lentner, 1970; Paul \& Southgate, 1976), to broccoli caused some depression in Fe absorption, there was a wide range of absorption from vegetables containing large amounts of oxalate. The bioavailability of the $\mathrm{Fe}$ in these vegetables therefore appeared to depend more on the presence of other inhibitors and enhancers. Two factors possibly responsible for the poor bioavailability of $\mathrm{Fe}$ in some of the vegetables were identified. Sodium phytate and the polyphenol, tannic acid, were shown in separate experiments to inhibit the absorption of vegetable $\mathrm{Fe}$, which is in line with previous findings (Hallberg \& Solvell, 1967; Disler, Lynch, Charlton, Torrance et al. 1975). It therefore seemed probable that the presence of certain phytates and polyphenols in food might have a similar effect and, indeed, $\mathrm{Fe}$ absorption was found to be uniformly poor in those vegetables such as wheat germ, butter beans and lentils that contain large amounts of $P$, presumably mostly in the form of phytates (van Soest, 1978). As far as polyphenols are concerned, we have previously shown that tea, which contains tannates, is a potent inhibitor of Fe absorption (Disler, Lynch, Charlton, Torrance et al. 1975). Suggestive evidence that polyphenols, of which tannates are an example, might be important inhibitors of vegetable Fe absorption, was obtained when Fe was added to two vegetables, namely aubergine and spinach. The bluish-black colour that developed suggested that they might contain significant amounts of phenolic compounds (Seikel, 1964), and that 
Fe was poorly absorbed despite the presence of adequate organic acids and little phytate. It was then observed that the other vegetables, including brown and green lentils and beetroot greens, that showed marked colour changes on the addition of $\mathrm{Fe}$, were also associated with poor Fe bioavailability. The total and extractable phenol contents of all the vegetables on which $\mathrm{Fe}$ absorption measurements had been done were therefore determined, and a strong inverse correlation between the total polyphenol content and $\mathrm{Fe}$ absorption was found $(r-0.859, P<0.001)$. The fact that the inverse correlation was even greater when the extractable polyphenol content had been subtracted from the total value $(r-0.901 ; P<0.001)$ suggested that it was the non-hydrolysable condensed polyphenols that were responsible for the inhibitory effect on $\mathrm{Fe}$ absorption.

The present findings have a relevance wider than that of the bioavailability of the $\mathrm{Fe}$ contained within the individual vegetables tested. The $\mathrm{Fe}$ content of vegetables varies considerably, and in some is low. However, the effect of the inhibitors and enhancers of $\mathrm{Fe}$ absorption which they contain is not confined to their endogenous $\mathrm{Fe}$, but extends to the whole pool of non-haem-Fe in the particular meal of which they form a part. In this context vegetables such as broccoli, cauliflower, cabbage and turnip exert a positive effect on Fe nutrition, while the opposite is the case with wheat germ, aubergine, butter beans, lentils and spinach.

This work was supported by a grant from the South African Atomic Energy Board.

\section{REFERENCES}

Apte, S. V. \& Iyengar, L. (1970). Am. J. clin. Nutr. 23, 73.

Bjorn-Rasmussen, E. \& Hallberg, L. (1974). Nutr. Metab. 16, 94.

Bothwell, T. H., Charlton, R. W., Cook, J. D. \& Finch, C. A. (1979). Iron Metabolism in Man. Oxford: Blackwell.

Conradie, J. D. \& Mbhele, B. E. L. (1980). S. Afr. med. J. 57, 282.

Cook, J. D., Layrisse, M., Martinez-Torres, C., Walker, R., Monsen, E. \& Finch, C. A. (1972). J. clin. Invest. 51, 805.

Cook, J. D. \& Monsen, E. R. (1976). Am. J. clin. Nutr. 29, 859.

Derman, D. P., Bothwell, T. H., MacPhail, A. P., Torrance, J. D., Bezwoda, W. R., Charlton, R. W. \& Mayet, F. G. H. (1980). Scand. J. Haemat. $25,193$.

Derman, D. P., Bothwell, T. H., Torrance, J. D., Bezwoda, W. R., MacPhail, A. P., Kew, M. C., Sayers, M. H., Disler, P. B. \& Charlton, R. W. (1980). Br. J. Nutr. 43, 271.

Derman, D., Sayers, M., Lynch, S. R., Charlton, R. W. \& Bothwell, T. H. (1977). Br. J. Nutr. $38,261$.

Diem, K. \& Lentner, C. (editors) (1970). Document Geigy Scientific Tables, 7 th ed. Basel, Switzeriand: J. R. Geigy S.A.

Disler, P. B., Lynch, S. R., Charlton, R. W., Bothwell, T. H., Walker, R. B. \& Mayet, F. (1975). Br. J. Nutr. 34, 141.

Disler, P. B., Lynch, S. R., Charlton, R. W., Torrance, J. D., Bothwell, T. H., Walker, R. B. \& Mayet, F. (1975). Gut 16, 193.

Disler, P. B., Lynch, S. R., Torrance, J. D., Sayers, M. H., Bothwell, T. H. \& Charlton, R. W. (1975). S. Afr. J. med. Sci. 40, 109.

Eakins, J. D. \& Brown, D. A. (1966). Int. J. appl. Radiat. Isotopes. 17, 391.

Hallberg, L. (1974). Proc. Nutr. Soc. 33, 285.

Hallberg, L. (1981). A. Rev. Nutr. 1, 123.

Hallberg, L. \& Bjorn-Rasmussen, E. (1972). Scand. J. Haemat. 9, 193.

Hallberg, L. \& Solvell, L.(1967). Acta Med. Scand. 181, 335.

International Commission for Radiation Proection (1960). Report of Committee 11 on Permissible Dose of Internal Radiation 1959. ICRP Publication no. 2. Oxford: Pergamon Press.

International Committee for Standardisation in Haematology (1978a). Br. J. Haemat. 38, 291.

International Committee for Standardisation in Haematology (1978 b). Br. J. Haemat. 38, 281.

Layrisse, M., Cook, J. D., Martinez-Torres, C., Roche, M., Kuhn, I. N., Walker, R. B. \& Finch, C. A. (1969). Blood 33, 430.

Layrisse, M., Martinez-Torres, C., Cook, J. D., Walker, R. \& Finch, C. A. (1973). Blood 41, 333.

MacPhail, A. P., Bothwell, T. H., Torrance, J. D., Derman, D. P., Bezwoda, W. R., Charlton, R. W. \& Mayet, F. G. H. (1981). S. Afr. med. J. 59, 939.

Martinez-Torres, C. \& Layrisse, M. (1973). In Clinics in Haematology, vol. 2, p. 339. [S. T. Callender, editor]. London, Philadelphia and Toronto: W. B. Saunders. 
Mayet, F. G. H., Adams, E. B., Moodley, T, Kleber, E. E. \& Cooper, S. K. (1972). S. Afr. med. J, $46,1427$.

Monsen, E. R., Hallberg, L., Layrisse, M., Hegsted, D. M., Cook, J. D., Mentz, W. \& Finch, C. A. (1978). Am. J. clin. Nutr. 31, 134.

Paul, A. A. \& Southgate, D. A. T. (1976). The Composition of Foods. Amsterdam: Elsevier North-Holland.

Rossander, L., Hallberg, L. \& Bjorn-Rasmussen, E. (1979). Am. J. clin. Nutr. 32, 2484.

Sayers, M. H., Lynch, S. R., Chariton, R. W., Bothwell, T. H., Walker, R. B. \& Mayet, F. (1974a). Br. J. Nutr. 31, 367.

Sayers, M. H., Lynch, S. R., Charlton, R. W., Bothwell, T. H., Walker, R. B. \& Mayet, F. (1974b). Br. J. Haemat. 28, 483.

Sayers, M. H., Lynch, S. R., Jacobs, P., Charlton, R. W., Bothwell, T. H., Walker, R. B. \& Mayet, F. (1973). Br. J. Haemat. 24, 209.

Seikel, M. K. (1964). In Biochemistry of Phenolic Compounds, p. 35 [J. B. Harbourne, editor]. New York: Academic Press.

Singleton, V. L. \& Rossi, J. A. (1965). In Methods for Analysis of Wines and Musts, p. 183 [M. A. Amerine and C. C. Ough, editors]. New York: J. Wiley and Sons.

South African Bureau of Standards (1972). Code of Practice for Medical use of Ionizing Radiations, Document 07.

Turnbull, A. L., Cleton, F. \& Finch, C. A. (1962). J. clin. Invest. 41, 1898.

van Soest, P. J. (1978). Am. J. clin. Nutr. 31, S12. 